\title{
Rheological Properties of Sweetened Sesame Paste Formulated with Bovine Blood Plasma
}

\author{
Diego F. Tirado*1, Katherine Paternina-Sierra ${ }^{\# 2}$, Diofanor Acevedo-Correa ${ }^{\# 3}$, Kevin José González- \\ Morelo $^{\# 4}$, Piedad Margarita Montero-Castillo ${ }^{\# 5}$ \\ * Department of Chemical Engineering, School of Chemistry, Universidad Complutense de Madrid, Av. \\ Complutense s/n, 28020, Madrid, Spain. \\ \# Department of Food Engineering, School of Engineering, Research Group Nutrición Salud y Calidad \\ Alimentaria (NUSCA), Universidad de Cartagena, Av. El Consulado, St. 30 No. 48-152. Cartagena de Indias, \\ Colombia. \\ 1ditirado@ucm.es, 2paternina185@gmail.com, ${ }^{3}$ diofanor3000@gmail.com \\ ${ }^{4}$ kevinjgonza@hotmail.com, ${ }^{5}$ pmargaritamontero@hotmail.com
}

\begin{abstract}
The aim of this study was to evaluate the rheological properties of a paste formulated with sesame (Sesamum indicum L.), syrup and bovine blood plasma. An experimental design under a multifactorial structure $2 \times 2 \times 4$ and middle fraction to rule out effects of similar treatment was used. Factors (with their respective levels) were: sesame paste content $(80 \%$ and $70 \%)$, syrup content $(20 \%$ and $30 \%$ ) and bovine blood plasma content $(0.75 \%, 1.00 \%, 1.25 \%$ and $1.50 \%)$. A total of 8 formulations with three replicates for each treatment were done. A pseudoplastic behavior for all studied samples was observed, typical of emulsions or suspensions. The paste exhibited predominating semi-solidlike behavior (elastic modulus, $G^{\prime}>$ viscous modulus, $\left.G^{\prime \prime}\right)$. This paste could be used in bakery products, with the purpose to improve their nutritional quality.
\end{abstract}

Keyword-Viscoelastic properties, elastic modulus $\left(\mathrm{G}^{\prime}\right)$, viscous modulus $\left(\mathrm{G}^{\prime \prime}\right)$, apparent viscosity, tangent of the phase angle $(\tan \delta)$

\section{INTRODUCTION}

Sesame paste (Sesamum indicum L.) is defined as a complex colloidal dispersion of oil rich in constituents as proteins and lipids [1], [2]. This paste is obtained by grinding the roasted and shelled seeds, without the addition or removal of any native component [3]. It is widely consumed in the Middle East and Asian cuisine with the purpose of providing foods with antioxidant compounds, high nutritional value, with regulatory properties and anti-cancer properties [4]. Sweetened sesame paste is called tehineh and it is used as an additive for bakery products and confectionery in India and Pakistan [1]. This paste contains a good amount of calcium, iron, potassium, phosphorus and vitamins $\mathrm{B}, \mathrm{C}$ and $\mathrm{E}[5]$.

Currently, in Colombia slaughterhouses generate high production of animal blood, and due to its low demand, this becomes an environmental problem, since much of this product is thrown into water sources [6], [7]. However, this blood can be used for human consumption because the bovine blood plasma, can be used in the formulation of foods as alow-cost protein source and also provides functional properties that enhance food quality [7]. This plasma is a translucent liquid obtained from the blood, denser than water and containing between $15 \%$ and $20 \%$ protein. Its wide use is due to the good properties of plasmatic proteins because it can act as emulsifying, gelling and/or stabilizer [6], [8].

On the other hand, the dynamic rheological tests allow to determine the ratio between the elastic and viscous component of a food, and quantify the extent that it behaves as semisolid or semiliquid through viscoelastic functions such as the complex modulus $\left(\mathrm{G}^{*}\right)$, defined before by several authors [9]-[11] as it is shown in Equation (1).

$G^{*}=\sqrt{G^{\prime 2}+G^{\prime \prime 2}}$

where $G^{\prime}$ is the storage modulus and represents the elastic component of the system and $G^{\prime \prime}$ is the loss modulus and represents its viscous character [10]-[12]. These modules are determined according to Equations (2) and (3).

$\begin{aligned} G^{\prime} & =\left(\frac{\tau_{0}}{\gamma_{0}}\right) \cos \delta \\ G^{\prime \prime} & =\left(\frac{\tau_{0}}{\gamma_{0}}\right) \operatorname{sen} \delta\end{aligned}$ 
where $\tau_{0}$ and $\gamma_{0}$ are the amplitudes of the waves of stress and strain, respectively, and $\delta$ is the phase angle. If the fluid is purely elastic it is satisfied that $\delta=0^{\circ}, \mathrm{G}^{*}=\mathrm{G}^{\prime}$ and $\mathrm{G}^{\prime \prime}=0$. In an ideal viscous fluid $\delta=90^{\circ}, \mathrm{G}^{*}=\mathrm{G}^{\prime \prime}$ and $\mathrm{G}^{\prime}=0$ [10]-[14]. Other viscoelastic functions are the complex viscosity $\left(\eta^{*}\right)$ and tangent of the phase shift or phase angle, more commonly called as $\tan \delta$ and popularly used to describe viscoelastic behavior [11]. These viscoelastic functions have been used to characterize some types of foods such as sweetened tamarind pulp [10], foam based on egg white [11], sesame based products like in this study [1], [15]-[19] and other food matrices [20]-[24].

It should be noted that the study of the rheology of pastes is essential in optimizing product development, manufacturing methodology and quality of the final product. Moreover, it is useful for to determinate the stability of foodstuffs [25]. Such interpretations provides guidelines in terms of theoretical mechanisms necessary to make sense of the observations related to the behavior of the composition and structure, predict and modify the properties as well as to compare an experimental method with another [11].One of the most used methods to characterize the viscoelasticity of fluid foods are dynamic rheological tests, which measure the amplitude of the shear response and phase angle by applying a slight deformation on a fluid in an oscillatory way [9].

By literature, there are few research on the rheological study of the type of pasta analyzed in this work, therefore, this study represents an important contribution to the improvement of these products in the industrial sector. According to the above, the objective of this research was to evaluate the rheological properties of sweetened sesame pastes from sesame (S. indicum L.) cultivated in the municipality of Córdoba, department of Bolivar (Colombia).

\section{MATERIALS AND METHODS}

\section{A. Samples}

Sesame (S. indicum L.) white setentanovariety from the mountainous region of the municipality of Córdoba, department of Bolívar (Colombia) and lyophilized bovine blood plasma supplied by Tecnas S.A. (Medellín, Colombia) were used. Other inputs used in the formulation (salt, sugar and glucose) were obtained in supermarkets from Cartagena de Indias, Colombia.

\section{B. Preparation of sesame paste}

The methodology for the production of technified sesame pasta previously reported [13], [26] have been used in this research. For the preparation of the sesame paste, $1 \mathrm{~kg}$ of sesame seeds were cleaned and shelled. Then they were immersed in $1 \times 10^{-3} \mathrm{~m}^{3}$ of water at room temperature for $12 \mathrm{~h}$. The soaked seeds were squeezed and shelled and then immersed for $5 \mathrm{~min}$ in saline solution at $230 \mathrm{~kg} \mathrm{~m}^{-3}$. This was repeated three times to separate the shells and other foreign elements, which were taken from the surface of the solution. Then, seeds were washed five times to remove salt. Afterwards, seeds were dried and toasted. For this, $0.25 \mathrm{~kg}$ of wet peeled seeds were roasted at $413.15 \mathrm{~K}$ in a compact oven (Challerger series 02451 ), for 30 min with stirring, avoiding overheating. Then the roasted seeds were ground twice in a grain mill.

\section{Preparation of syrup}

Water solution at a mass fraction of $50 \%$ sugar was made. Then, $0.03 \mathrm{~kg}$ liquid glucose $\mathrm{kg}^{-1}$ sugar was added. After having prepared the syrup and using a homogenizer, sesame paste and $50 \%$ of plasma was mixed for $30 \mathrm{~s}$ and $2 \mathrm{rpm}$. Then, the syrup was slowly added between $2 \mathrm{rpm}$ and $4 \mathrm{rpm}$ for $2 \mathrm{~min}$. Afterwards, $50 \%$ of excess plasma was mixed for 3 min, making good homogenate. It is important to emphasize that the syrup could not be hot, because it would facilitate the separation of oil from the sesame paste.

\section{Rheological measurements}

Viscoelastic measurements were carried out using the methodology proposed by Tirado et al., [10], [11]. For this, each sample was submitted to strain sweep tests and deformation was determined in the linear viscoelastic range. A frequency sweep was performed in a range between $0.1 \mathrm{~Hz}$ and $100 \mathrm{~Hz}$. A range between $3 \mathrm{~Hz}$ and 50 $\mathrm{Hz}$ was used for the measurement of apparent viscosity. The temperature of samples was maintained at 298.15 $\mathrm{K} \pm 0.1 \mathrm{~K}$. Tests were carried out in a rheometer TA AR $1500 \AA$ (TA Instruments Ltda.) by using a plate of 40 $\mathrm{mm}$ which was controlled by the TA Universal Analysis Version $5.2{ }^{\circledR}$ software, previously installed in a computer connected to the rheometer. Rheological data analysis was performed using Rheology Advantage Data Analysis Version $5.7 \circledR$ software. Storage $\left(\mathrm{G}^{\prime}\right)$ and loss modulus $\left(\mathrm{G}^{\prime \prime}\right)$, as well as loss tangent values $(\tan \delta)$ were determined through oscillatory test, which relied on the deformation frequency. All samples were kept for 15 min of relaxation time before performing the tests.

\section{E. Experimental design and statistical analysis}

An experimental design with a $2 \times 2 \times 4$ multifactorial structure and mid fraction to rule out effects of similar treatment was used. Factors (with their respective levels) were: sesame paste content ( $80 \%$ and $70 \%$ ), syrup content $(20 \%$ and $30 \%)$ and bovine blood plasma content $(0.75 \%, 1.00 \%, 1.25 \%$ and $1.50 \%)$. A total of 8 formulations with three replicates of each treatment were done. The response variables were the viscoelastic 
functions: elastic $\left(\mathrm{G}^{\prime}\right)$ and viscous modulus $\left(\mathrm{G}^{\prime \prime}\right)$, complex viscosity $\left(\eta^{*}\right)$ and the tangent of the phase angle (tan $\delta)$. The formulations of each treatment are shown in Table 1.

Table 1. Formulations of the sweetened sesame pastes

\begin{tabular}{ccccc}
\hline Block & Treatment & Sesame paste (\%) & Syrup (\%) & Plasma (\%) \\
\hline 1 & T1 & 70 & 30 & 0.75 \\
1 & T2 & 70 & 30 & 1.00 \\
1 & T3 & 70 & 30 & 1.25 \\
1 & T4 & 70 & 30 & 1.50 \\
2 & T5 & 80 & 20 & 0.75 \\
2 & T6 & 80 & 20 & 1.00 \\
2 & T7 & 80 & 20 & 1.25 \\
2 & T8 & & 20 & 1.50 \\
\hline
\end{tabular}

\section{III.RESULTS AND DISCUSSIONS}

In Fig. 1, flow curves of sesame pastes of the four treatments from the first block ( $70 \%$ sesame paste and 30 $\%$ syrup) are presented. According to Fig. 1, treatments with fewer plasma added had lower apparent viscosityshear rate relationship. It is emphasized that, even though at a shear rate of $3.16 \mathrm{~s}^{-1} \mathrm{~T} 4 \mathrm{had}$ a greater slope than the other treatments, at a shear rate of $3.98 \mathrm{~s}^{-1}$, the viscosity was less than T3. So, T3 had the highest apparent viscosity-shear rate relationship compared to other treatments.

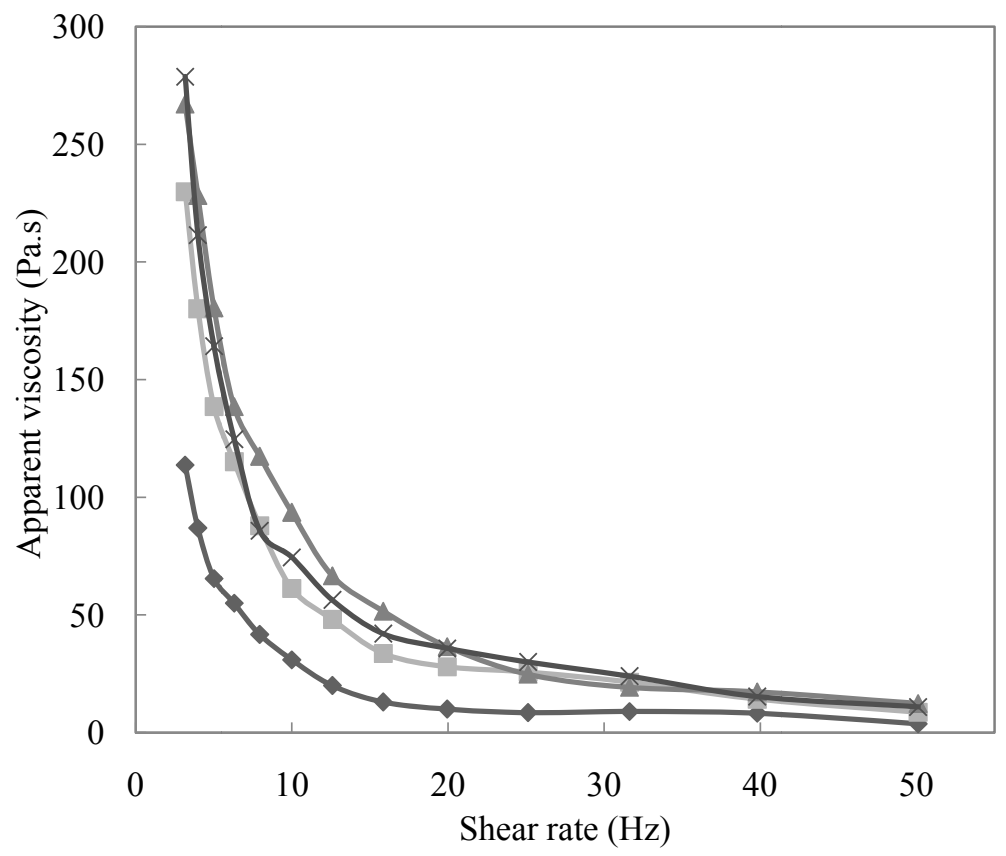

Fig. 1. Apparent viscosity-shear rate relationship for treatments $\mathrm{T} 1(\neg), \mathrm{T} 2(--), \mathrm{T} 3(-\leftarrow)$ and $\mathrm{T} 4(\longleftarrow$ ) .

On the other hand, Fig. 2 shows that treatments from the second block of sweetened paste ( $80 \%$ paste and 20 $\%$ sesame syrup) showed different behavior than the first treatments, because in these, the effect caused for the bovine blood plasma was not significant, possibly due a higher sesame paste content, showing that treatment with lower content of plasma had a higher apparent viscosity-shear rate relationship. However, in general, a pseudoplastic flow or shear thinning behavior was evident for all studied treatments, typical of pseudoplastic suspensions or emulsions. Such behavior is characterized by a decrease in viscosity with increasing shear rate, that is, when the strain rate increases resistance to flow decreases [11]. 


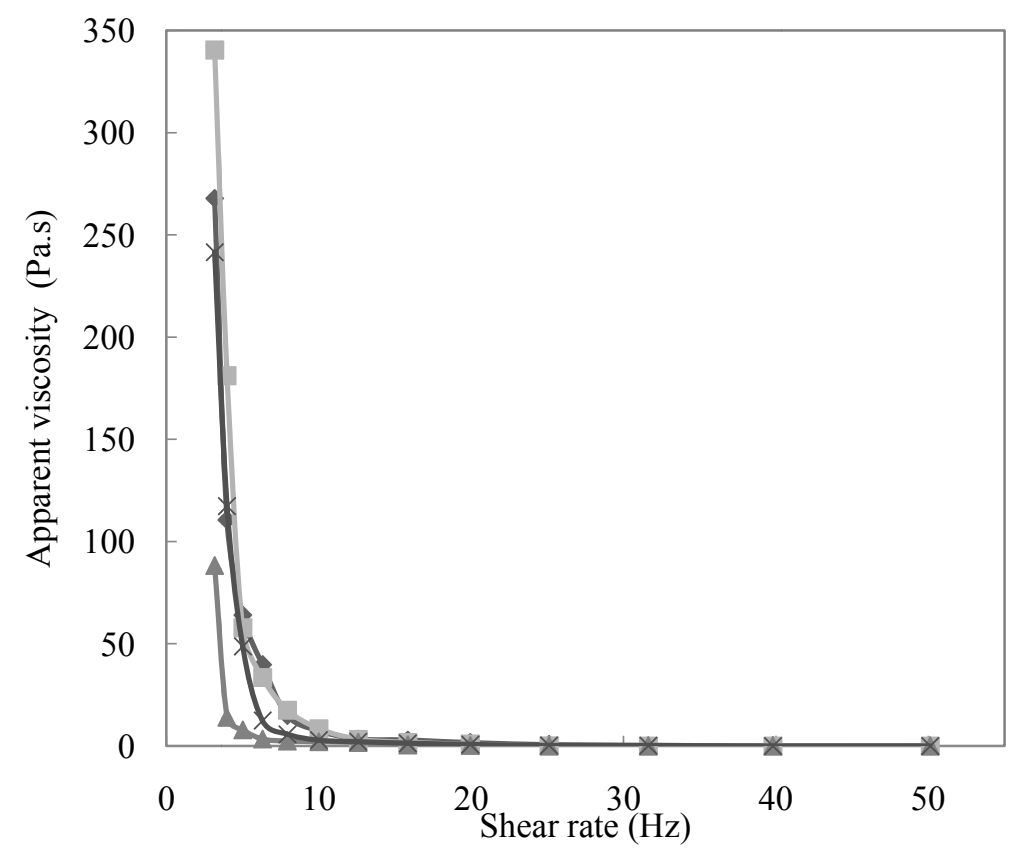

Fig. 2. Apparent viscosity-shear rate relationship for treatments T5 $(\bullet-)$, T6 $(--)$, T7 $(\neg-)$ and T8 $(*$ ).

For all treatments, experimental results of apparent viscosity versus shear rate were found to exhibit a nonNewtonian behavior. Apparent viscosity of blends decreased with increasing shear rate. The decrease in apparent viscosity with increasing shear rate could be explained by the structural breakdown of the blend due to the hydrodynamic forces generated and the increased alignment of the constituent molecules [17]. Shearing causes progressive deformation and disruption of oil droplets, resulting in less resistance to flow. Shear induced structural breakdown related to oil droplet deflocculation has also been reported by Arslan et al.,[17].

These results agreed with those reported by other authors [2], [11]-[13], [16], [24], [27]. For example, AbuJdayil[16] investigated the steady and time-dependent flow properties of halawa tehineh in the temperature range between $298.15 \mathrm{~K}$ and $318.15 \mathrm{~K}$, noting that the flow behavior of halawa tehineh was pseudoplastic and thixotropic at all temperatures measured, since continuous measurements of viscosity by increasing and continuous decrease in the shear rate indicated that the sweetened tehineh paste exhibited shear thinning behavior. In the same way, Arslan et al.,[17] determined rheological properties of tahin/pekmez(tehineh/grape juice concentrate) blends at different tahin concentrations (from $20 \%$ to $32 \%$ ) and temperatures (from 308.15 $\mathrm{K}$ to $338.15 \mathrm{~K}$ ). They found that in all conditions tested mixtures showed a shear thinning behavior. Meanwhile, Razaviet al.,[18] determined the rheological behavior of reduced fat sesame paste/date syrup blends at temperature between $298.15 \mathrm{~K}$ and $323.15 \mathrm{~K}$, concluding, similar to investigations aforementioned, that all sesame paste/date syrup blends were found to exhibit non-Newtonian, pseudoplastic behavior at all temperatures and fat substitute levels.

Changes in storage $\left(G^{\prime}\right)$ and loss modulus $\left(G^{\prime \prime}\right)$ for sweetened pastes obtained from dynamic viscoelastic tests in function of frequency can be seen in Fig. 3. The mechanical spectrum shows, in both cases, the same trend with the frequency, thus $G^{\prime}$ values were higher than $G^{\prime \prime}$ throughout the frequency range studied, indicating that these samples had notable viscoelastic properties. This means that these systems had a tendency to form a macromolecular network with prominent elastic properties, therefore, sweetened sesame paste behaved as a semi-solid, indicative of strong particle-particle interactions or a network-like structure stabilized [10]-[13], [28]. Furthermore, Figure 3 shows that the group of formulations with $80 \%$ sesame paste and $20 \%$ syrup had the highest storage function throughout the frequency range, which shows predominance of elastic properties in this group. This could be probably because having the highest content of sesame paste, they form more complex structures with plasma, highlighting the viscoelastic character. This phenomenon could be interpreted due to the existence of well-developed elastic nets [11], [29]. 


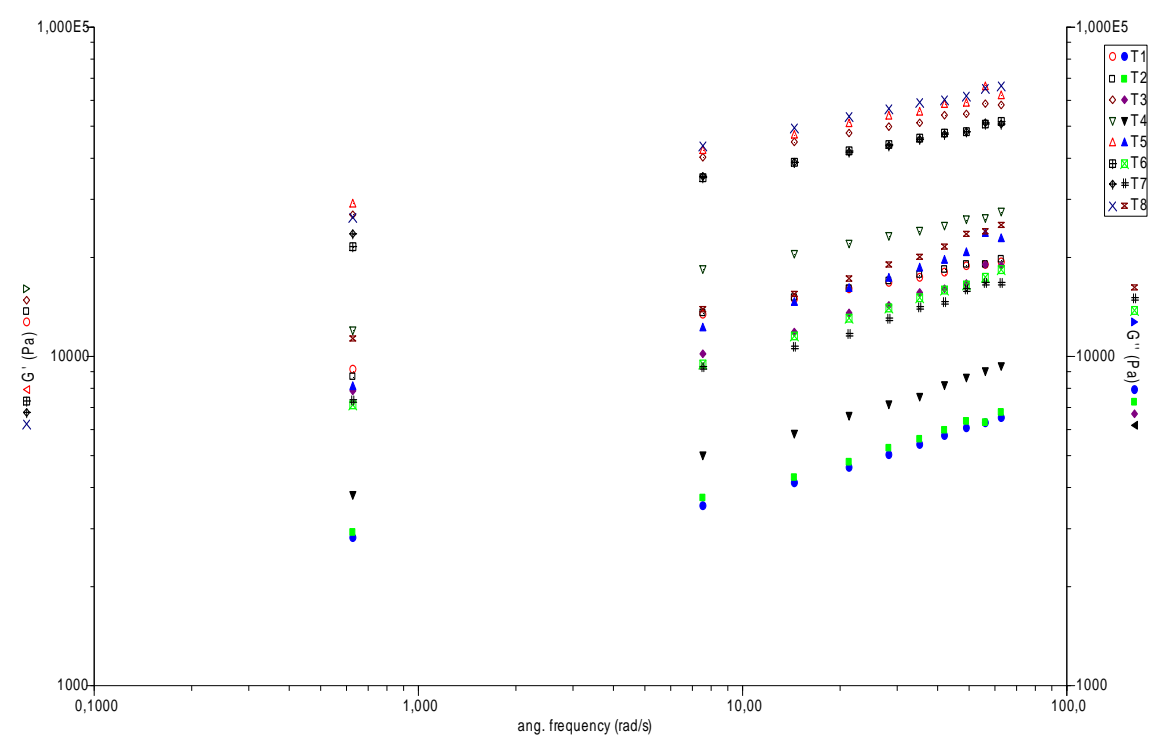

Fig. 3. Elastic $\left(\mathrm{G}^{\prime}\right)$ and viscous modulus $\left(\mathrm{G}^{\prime \prime}\right)$ over changing frequencies for sweetened sesame paste samples.

The results observed on the viscoelastic behavior of sweetened sesame paste of this research coincided with those reported by Çiftçiet al.,[2] for sesame paste; Acevedo et al., [12] for technified sesame pasta; Tirado et al., [10] for sweetened tamarind pulp and Abu-Jdayilet al., [1] for a kind of sweetened sesame paste (tehineh). The aforementioned authors, as in this work, found in their studies that the magnitudes of the storage ( $\left.G^{\prime}\right)$ and loss modules $\left(G^{\prime \prime}\right)$ of samples increased with frequency, reporting a predominance of elastic properties over viscous $\left(\mathrm{G}^{\prime}>\mathrm{G}^{\prime \prime}\right)$.

Values of the tangent of the phase angle $(\tan \delta)$ for paste treatments studied are represented in Fig. 4. The loss function compared the amount of energy lost during an oscillatory test with the amount of stored energy during this period, indicating the predominance of elastic or viscous property. As Fig. 4 shows, on the frequency range studied, the values of loss tangent were always less than unity. This fact demonstrated the predominantly elastic character of samples, which could be related to a high degree of structuring in the sample [11].

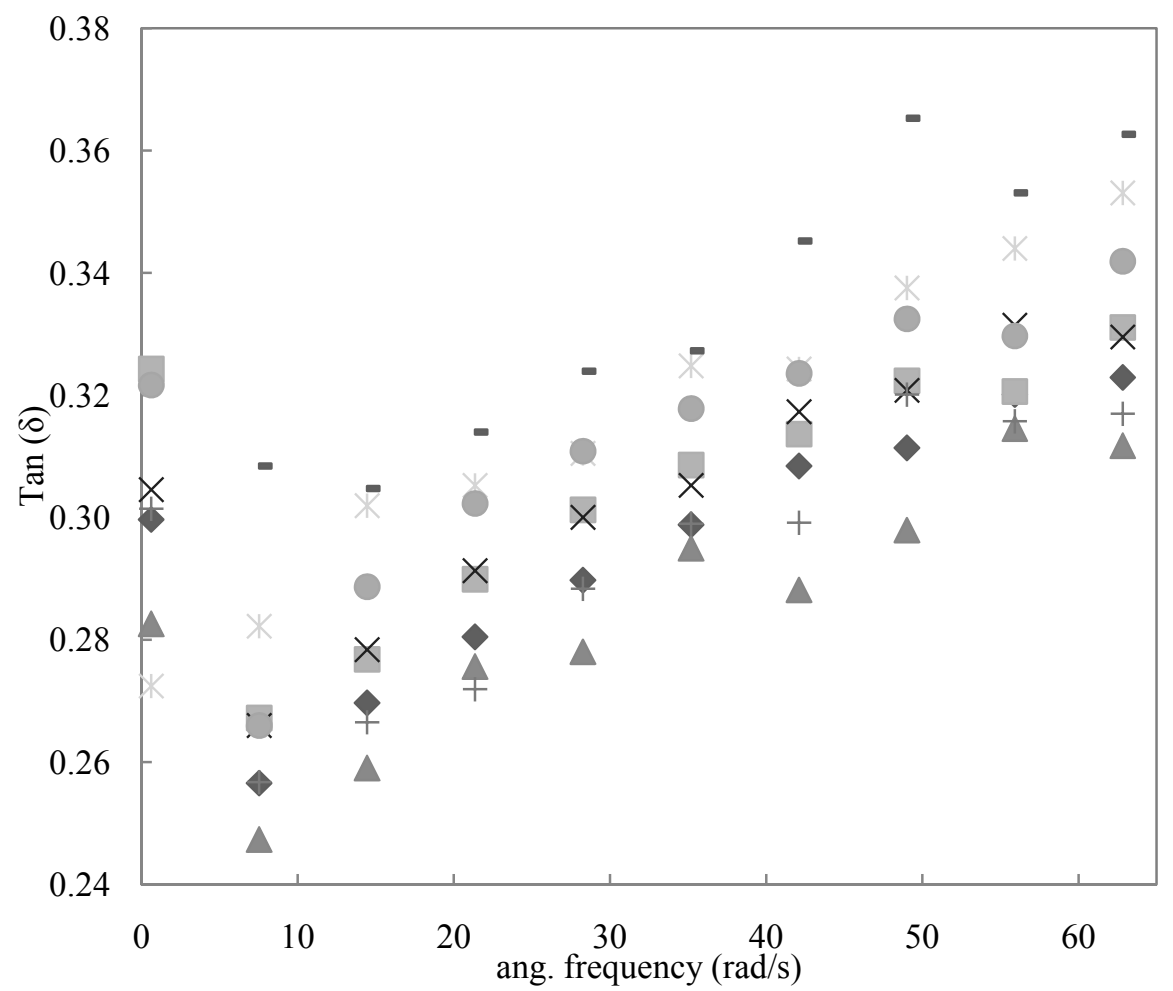

Figure 4. Tangent of the phase angle $(\delta)$ over changing frequencies for sweetened sesame paste of treatments T1 $(\diamond)$, T2 $(\square)$, T3 $(\Delta)$, T4 $(\times)$, T5 $(*)$, T6 $(\bullet)$, T7 $(+)$ and T8 $(\bullet)$. 
In this work was not considered the distribution of particle size, however, this should be studied further in future research, because it could play an important role in the rheological properties and colloidal stability of sweetened sesame pastes analyzed in this research.

\section{CONCLUSIONS}

It could be concluded that in all samples tested, viscosity decreased when increased shear rate, showing pseudoplastic behavior, typical of emulsions. For samples with $70 \%$ sesame paste and $30 \%$ syrup, the plasma concentration had a significant effect because samples with fewer plasma added, had lower apparent viscosityshear rate relationship. Meanwhile, the magnitudes of the storage $\left(G^{\prime}\right)$ and loss modules $\left(G^{\prime \prime}\right)$ of sweetened paste samples increased with the frequency, showing a predominance of elastic properties over viscous, so the paste exhibited predominating semi-solid-like behavior (elastic modulus $>$ viscous modulus). Furthermore, the fact that the values of loss tangent were always less than unity evidence the predominantly elastic nature of the samples, which could be related to a highly-structured degree inside them.

\section{ACKNOWLEDGMENT}

Authors are grateful to the Universidad de Cartagena andthe Administrative Department of Science, Technology and Innovation (COLCIENCIAS)for the financial support to the project 110766441920 that was granted to the Research Group Nutrición, Salud y Calidad Alimentaria (NUSCA) in the call 664-2014.

\section{REFERENCES}

[1] B. Abu-Jdayil, K. Al-Malah, and H. Asoud, "Rheological characterization of milled sesame (tehineh)," Food Hydrocolloids, vol. 16, no. 1, pp. 55-61, 2002.

[2] D. Çiftçi, T. Kahyaoglu, S. Kapucu, and S. Kaya, "Colloidal stability and rheological properties of sesame paste,” Journal of Food Engineering, vol. 87, no. 3, pp. 428-435, 2008.

[3] F. Aloui, B. Maazoun, Y. Gargouri, and N. Miled, "Optimization of oil retention in sesame based halva using emulsifiers and fibers: an industrial assay," Journal of Food Science and Technology, vol. 53, no. 3, pp. 1540-1550, 2016.

[4] M. V. Reshma, C. Balachandran, C. Arumughan, A. Sunderasan, D. Sukumaran, S. Thomas, and S. S. Saritha, "Extraction, separation and characterisation of sesame oil lignan for nutraceutical applications," Food Chemistry, vol. 120, no. 4, pp. 1041-1046, 2010.

[5] N. Prasad, K. R. Sanjay, and D. Prasad, "A Review on Nutritional and Nutraceutical Properties of Sesame," Journal of Nutrition \& Food Sciences, vol. 2, no. 2, pp. 1-6, 2012.

[6] D. F. Tirado, P. M. Montero, and D. Acevedo, "Sensory acceptability and microbiological quality of rice based drinks and bovine and porcine plasma," Información tecnológica, vol. 26, no. 6, pp. 45-54, 2015.

[7] L. J. Gómez, O. A. Figueroa, and J. E. Zapata, "Antioxidant activity of bovine plasma enzymatic hydrolysates obtained by effect of Alcalase ${ }^{\circledR} 2.4$ L,” Información tecnológica, vol. 24, no. 1, pp. 33-42, 2013.

[8] P. M. Montero, D. Acevedo, A. J. Arnedo, and N. K. Miranda, "Effect of the Addition of Sesame Paste and Bovine Blood Plasma in the Development of a Meat Product Type Sausage,” Información tecnológica, vol. 26, no. 6, pp. 55-64, 2015.

[9] S. Gunasekaran and M. M. Ak, "Dynamic oscillatory shear testing of foods — selected applications," Trends in Food Science \& Technology, vol. 11, no. 3, pp. 115-127, 2000.

[10] D. F. Tirado, D. Acevedo, and P. Montero, "Rheological properties of sweetened tamarind pulp," Revista U.D.C.A Actualidad \& Divulgación Científica, vol. 17, no. 2, pp. 495-501, 2014.

[11] D. F. Tirado, D. Acevedo, and R. Torres, "Rheological characterization of a foam based on egg white, sugar and tamarind pulp," Revista U.D.C.A Actualidad \& Divulgación Científica, vol. 18, no. 2, pp. 465-473, 2015

[12] D. Acevedo, C. Granados, and R. Torres, "Rheological characterization of a Fermented Milk Product known as Suero Costeño from Turbaco, Arjona, El Carmen de Bolívar and a Commercial Product (Colombia),” Información Tecnológica, vol. 25, no. 3, pp. 3-10, 2014.

[13] D. Acevedo, P. Montero, and Y. Marrugo, "Evaluation of rheological properties of artisan and technified sesame pasta," Revista U.D.C.A Actualidad \& Divulgación Científica, vol. 16, no. 1, pp. 245-251, 2013.

[14] R. P. Chhabra and J. F. Richardson, Non-Newtonian Flow and Applied Rheology. Elsevier, 2008.

[15] B. Abu-Jdayil, "Modelling the time-dependent rheological behavior of semisolid foodstuffs," Journal of Food Engineering, vol. 57, no. 1, pp. 97-102, 2003.

[16] B. Abu-Jdayil, "Flow properties of sweetened sesame paste (halawa tehineh)," European Food Research and Technology, vol. 219, no. 3, pp. 265-272, 2004

[17] E. Arslan, M. E. Yener, and A. Esin, "Rheological characterization of tahin/pekmez (sesame paste/concentrated grape juice) blends," Journal of Food Engineering, vol. 69, no. 2, pp. 167-172, 2005.

[18] S. M. A. Razavi, M. B. Habibi Najafi, and Z. Alaee, "The time independent rheological properties of low fat sesame paste/date syrup blends as a function of fat substitutes and temperature," Food Hydrocolloids, vol. 21, no. 2, pp. 198-202, 2007.

[19] O. Guneser and M. Zorba, "Effect of emulsifiers on oil separation problem and quality characteristics of Tahin Helva during storage," Journal of Food Science and Technology, vol. 51, no. 6, pp. 1085-1093, 2014.

[20] A. Shukla and S. S. H. Rizvi, "Viscoelastic Properties of Butter," Journal of Food Science, vol. 60, no. 5, pp. 902-905, Sep. 1995.

[21] M. Castillo, J. A. Lucey, T. Wang, and F. A. Payne, "Effect of temperature and inoculum concentration on gel microstructure, permeability and syneresis kinetics. Cottage cheese-type gels," International Dairy Journal, vol. 16, no. 2, pp. 153-163, Feb. 2006.

[22] R. Jena and S. Bhattacharya, "Viscoelastic characterization of rice gel," Journal of Texture Studies, vol. 34, no. 4, pp. 349-360, Oct. 2003.

[23] L. Campo and C. Tovar, "Influence of the starch content in the viscoelastic properties of surimi gels," Journal of Food Engineering, vol. 84, no. 1, pp. 140-147, 2008.

[24] D. F. Tirado, A. Vertel-Gallego, J. Lora-Sánchez, L. A. Gallo-García, D. Acevedo, and R. Torres-Gallo, "Rheological properties of Colombian-Caribbean-coast sour cream from goat milk," International Journal of Food Science \& Technology, p. DOI 10.1111/ijfs.13562, 2017.

[25] F. Yuksel and A. Kayacier, "Utilization of stale bread in fried wheat chips: Response surface methodology study for the characterization of textural, morphologic, sensory, some physicochemical and chemical properties of wheat chips," LWT - Food Science and Technology, vol. 67, pp. 89-98, 2016. 
[26] D. Acevedo, P. M. Montero, and Y. A. Marrugo, "Study of the rheological properties of artisanal and technified pastas of oily sesame (Sesamum indicum) grown in Zambrano-Bolívar (Colombia)," Información tecnológica, vol. 25, no. 4, pp. 73-78, 2014.

[27] F. Lokumcu Altay and M. M. Ak, "Effects of temperature, shear rate and constituents on rheological properties of tahin (sesame paste)," Journal of the Science of Food and Agriculture, vol. 85, no. 1, pp. 105-111, Jan. 2005.

[28] M. Contreras-Padilla, M. E. Rodríguez-García, E. Gutiérrez-Cortez, M. del C. Valderrama-Bravo, J. I. Rojas-Molina, and E. M. Rivera-Muñoz, "Physicochemical and rheological characterization of Opuntia ficus mucilage at three different maturity stages of cladode," European Polymer Journal, vol. 78, pp. 226-234, 2016.

[29] S. Thaiphanit, G. Schleining, and P. Anprung, "Effects of coconut (Cocos nucifera L.) protein hydrolysates obtained from enzymatic hydrolysis on the stability and rheological properties of oil-in-water emulsions," Food Hydrocolloids, vol. 60, pp. 252-264, 2016.

\section{AUTHOR PROFILE}

Diego F. Tirado is a doctorate student in Chemical Engineering at the Universidad Complutense de Madrid (Spain). Mr. Tirado has a bachelor degree in Food Engineering and a master degree in Environmental Engineering from the Universidad de Cartagena (Colombia).

Katherine Paternina-Sierra works as research assistant in the Research Group NUSCA. Ms. PaterninaSierrahas a bachelor degree in Food Engineering from the Universidad de Cartagena.

Diofanor Acevedo-Correaworks as a full-time professor at the Universidad de Cartagena. Dr. Acevedo has a doctoral degreein Food Engineering from the Universidad del Valle (Colombia). Furthermore, he has bachelor degrees in Food Engineering and Pharmaceutical Chemistry from the Universidad de Cartagena. He is full-time researcher of the Research Group NUSCA.

Kevin José González-Moreloworks as research assistant in the Research Group NUSCA and has a bachelor degree in Food Engineering from the Universidad de Cartagena.

Piedad Margarita Montero-Castilloworks as a full-time professor at the Universidad de Cartagena. Dr. Montero-Castillohas a doctoral degree in Sciences from the Universidad Rafael BellosoChacín(Venezuela). She also has a master degree in Food Science and Technology and a bachelor degree in Food Engineering from the Universidad del Zulia (Venezuela) and the Universidad de la Salle (Colombia), respectively. She is director of the Research Group NUSCA. 